\title{
Data Storage Based Heart and Body Temperature Measurement Device
}

\author{
Nur Hudha Wijaya ${ }^{1}$, Andi Gofer Alvian², Afif Zuhri Arfianto ${ }^{3}$, Joessianto Eko Poetro ${ }^{4}$, Farhad Waseel ${ }^{5}$ \\ ${ }^{1,2}$ Program Studi Teknik Elektromedik, Universitas Muhammadiyah Yogyakarta, Yogyakarta Indonesia \\ ${ }^{3,4}$ Politeknik Perkapalan Negeri Surabaya, Surabaya, Indonesia \\ ${ }^{5}$ Department of mathematics, Kabul University, Kabul, Afghanistan \\ Email: ${ }^{1}$ nurhudhawijaya@umy.ac.id, andigoferalvian@umy.ac.id, ${ }^{3}$ afifzuhri@ieee.org, ${ }^{4}$ joessianto@ppns.ac.id, \\ ${ }^{1}$ Farhadwaseel@ku.edu.af
}

\begin{abstract}
Body health is the most important thing for human life. The heart is one of the organs of the body that is very important for humans. The heart functions to regulate the circulation of oxygen-rich blood and to carry leftover food in the body. Heart rate illustrates how hard the heart works. The heart rate needs to be monitored to find out the patient's condition. BPM measurement and temperature is an activity of measuring heart rate and body temperature. The patient's body temperature affects the patient's rapid heart to pump blood throughout the body. The study aims to design a heart rate and body temperature measuring device using an infrared LED as a transmitter and a photodiode as a receiver, an LM35 as the temperature sensor, and an LCD to display the final output. This tool uses an ATMega8 microcontroller as the controlling system. The device was completed with data storage and temperature indicators. The result of the test on the device showed that the device performed very well in measuring the heart rate and body temperature of adult patients aged 20 until 40 years old.
\end{abstract}

Keywords - Heart rate, Body temperature, Finger sensor, LM35, Microcontroller, ATMega8, LCD

\section{INTRODUCTION}

An examination of vital signs is a fast and efficient way to monitor a patient's condition or identify problems and evaluate responses. The examination provides basic information that allows further actions. Four components of the main vital signs that must be monitored routinely are blood pressure, pulse rate, respiratory frequency, and body temperature. If a patient is suspected of suffering from a serious medical condition that can affect his life, the vital signs will be monitored repeatedly and evaluation will continue to be carried out to assess the progress until the value of normal vital signs is obtained.

BPM is the number of heartbeats in one minute. A normal pulse for healthy adults is between 60 and 100 BPM. Bradycardia occurs when the pulse rate is below 60 per minute, while tachycardia occurs when the heart rate is above 100 BPM. The working principle of this diagnostic tool is to count the number of heartbeats in units of minutes, from the results of the heart rate calculation can be determined the condition of the patient in normal or abnormal conditions will be displayed on the LCD screen.

Body temperature is the difference between the amount of heat produced by the body and the amount of heat loss. The
LM35 sensor is placed in the armpit to measure the patient's body temperature. Monitoring and measuring body temperature is very important to know the condition of the patient. A healthy body is able to maintain body temperature constantly even in changing environmental conditions. Normal temperatures in adults range from $36.5^{\circ} \mathrm{C}-37.5^{\circ} \mathrm{C}$. If the body temperature is below $36^{\circ} \mathrm{C}$, it indicates hypothermia, whereas if the body temperature is more than $37.5^{\circ} \mathrm{C}$ it indicates hyperthermia. Body temperature has a relationship with the number of heartbeats, a slight change in body temperature can have a large effect on the performance of the heart because of the higher the patient's temperature, the faster the heart pumping blood throughout the body.

Some researchers have conducted research on heart rate and body temperature. Mohammedsheet and Aziz designed and implemented a digital heart rate counter using an 8051 microcontroller [1]. The system consisted of a finger-tip infrared sensor, an AT89S51 microcontroller, and an LCD display. Trivedi and Cheeran studied heart rate monitoring of android-based health parameters [2]. The system was monitored by the Android heart rate and body temperature. However, it couldn't save the data obtained. Valipour and Abbasi-Kesbi designed a heart and respiratory rate sensor based on phonocardiogram for health care applications [3]. The system used two sensors in the form of a mini wireless acoustic sensor to detect heart rate and respiratory sounds, using raspberries, and monitors.

Lichtman examined the smart electrocardiogram monitoring system on Android [4]. The system consisted of ECG sensors to determine heart rate, signal processor, and Android. The system monitored the patient's heart rate. Patil studied android applications for driver assistance and event alert systems using ultrasonic sensors and heart rate sensors [5]. The system consisted of ultrasonic sensors, heart rate sensors, raspberry pi, and android. It was used to determine the heart rate and condition of the driver. Al-Shaher and AlKhafaji investigated e-health system for monitoring vital signs [6]. The system used blood pressure sensors, heart rate, and blood sugar, microcontroller and ZigBee. It was used to monitor the patient's vital signs.

Wasnik and Jeyakumar designed a monitoring device to measure the stress level parameters of computer users [7]. The system consisted of ultrasonic sensors, accelerometers, an Arduino microcontroller, and an Android. The system 
monitored stress levels by using a heart rate indicator. Aziz investigated smart real-time health monitoring and tracking systems using GSM/GPS technology [8]. The system consisted of a heart rate and body temperature sensor, an Arduino microcontroller and a GPS/GSM module. It monitored a person's health level and knows his position. Kuruppuachchi, Perera, and Meegama examined wireless sensor nodes for simultaneous monitoring of health parameters [9]. The system used temperature sensors, an Arduino, a Wi-Fi module, and a smartphone.

Kokalki studied smart health tapes using IoT [10]. The system consisted of a temperature sensor, a heart rate sensor, an Arduino Uno microcontroller, and an android. It monitored temperature and heart rate. Anand studied the performance improvement of a portable home E-health monitoring system [11]. The system consisted of temperature sensors, an ECG, an LPC-2148 microcontroller and an SMS module. It monitored the patient's heart rate, body temperature, and it detected brain tumor. Mahmood Developed wireless body area networks for long-distance patient health observation [12]. he system used ECG sensors to detect heart rate, and body temperature and accelerator sensors to detect when the patients fall. It monitored the patient's condition remotely using Wi-fi and GSM.

Some research on the design of microcontroller-based heart rate measurement design has been previously carried out. The device worked using optical technology as a sensor to detect blood flow in the skin in the fingertip radial artery. Based on the research, new innovations, and equipment by adding a diagnosis of normal hyperthermia, hypothermia to temperature, normal bradycardia and tachycardia for BPM in adult patients and equipped with data storage is necessary.

\section{METHOD}

The method to design and make the device was divided into three stages namely hardware design, software design and testing for data retrieval. The description of the method shown in the blog diagram in Figure 1.

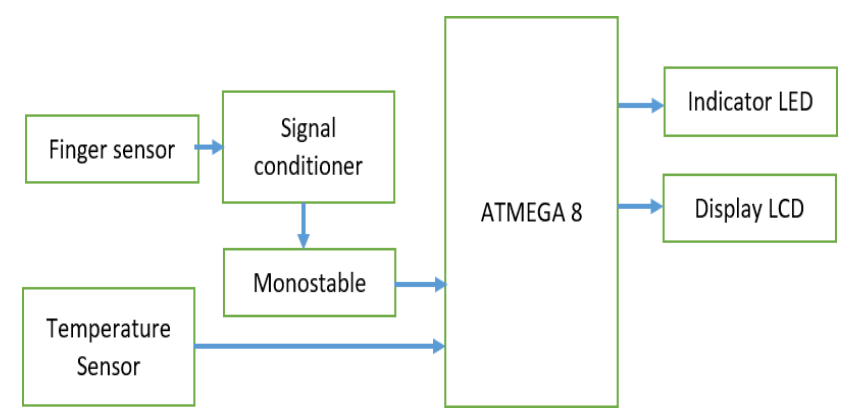

Fig. 1. Block diagram of the heart rate measuring device

The current flows to supply the voltage needed by all the circuits through the step up. The LM35 sensor [13]-[17] is attached to the armpit of the patient and the finger sensor clamped the fingers for heart rate measurement as shown in Figure 2 [1], [18]. The LM35 sensor detects body temperature. Every change in body temperature will change the voltage. The LM35 sensor output enters the micro input, then processed in a microcontroller to calculate the patient's body temperature value. The finger sensor [19]-[23] contains an infrared LED that lights up and illuminates the fingers and a photodiode that is sensitive to light intensity. This light intensity will then be received by the photodiode. Analog signals from the photodiode are processed in the comparator circuit. These analog data/signals are amplified by a noninverting amplifier circuit. The analog data/signals produced will be compared with the comparator reference for further triggering the monostable input so that it can provide high or low logic to the micro input, then it will be processed in the microcontroller to calculate the patient's BPM value. The microcontroller will read how many triggers come in for 30 seconds. The data obtained for 30 seconds will be displayed on the LCD and make the BPM turn on the light indicator.

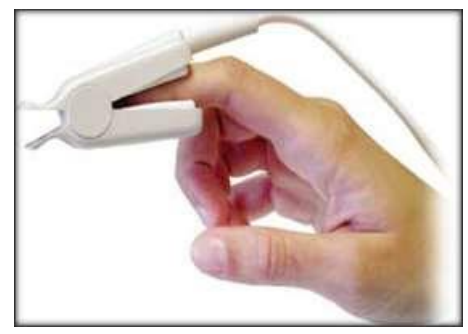

Fig. 2. Finger sensor

Based on the block diagram, a supporting software on the heart rate and body temperature measuring module is needed. Data storage using ATMega8 is required to operate it. The software used in the module work system is Code Vision AVR Software. Figure 3 shows the flow diagram of the system.

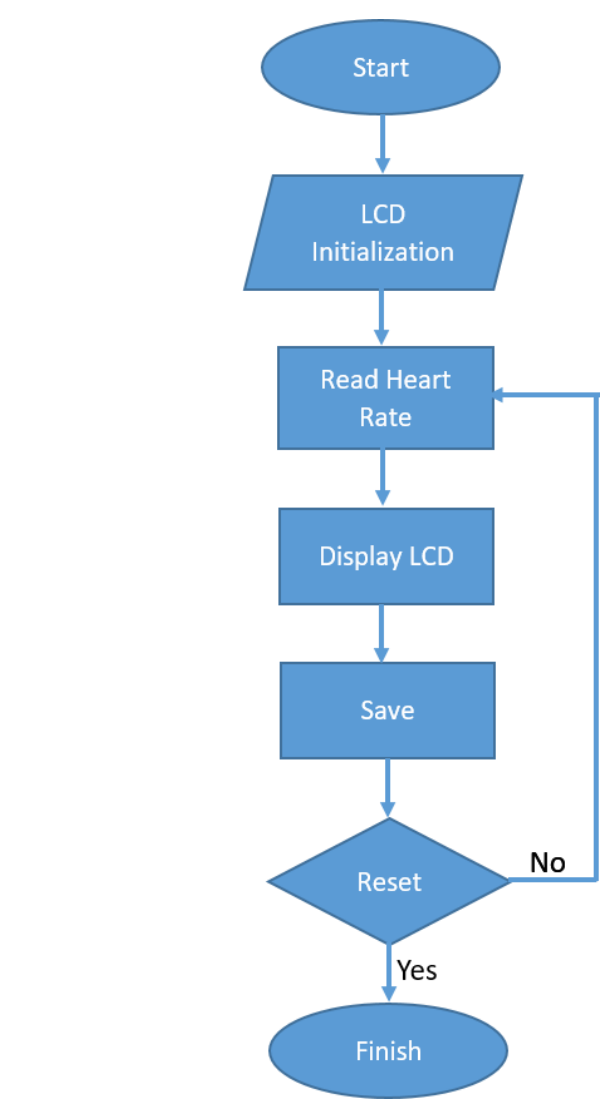

Fig. 3. Flowchart

The sensor starts to work after the device has run initialization on the microcontroller [24]-[30] output input and LCD interface. After the sensor is attached to the patient, 
the device will start to take data on respiratory rate and heart rate for 30 seconds. If the result of the heart rate $<60$ bradycardia dialog will appear, 60-100 indicates normal, > 100 indicates tachycardia. Normal body temperature in adults ranges from $36.5^{\circ} \mathrm{C}-37.5^{\circ} \mathrm{C}$. The temperature $<36^{\circ} \mathrm{C}$ indicates hypothermia, and $>37.5^{\circ} \mathrm{C}$ indicates hyperthermia. The main controller of this device is the minimum system shown in Figure 4.

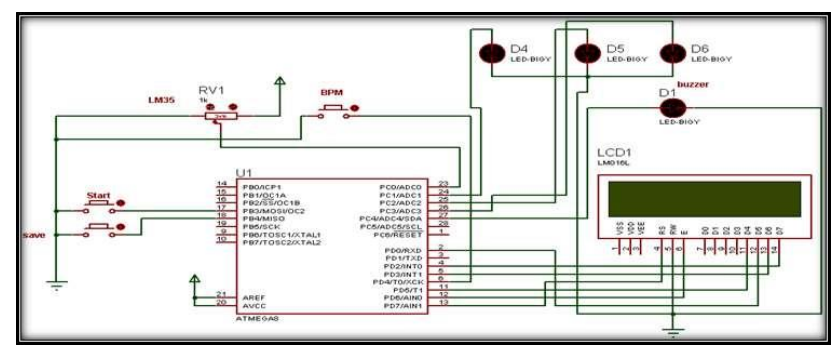

Fig. 4. Schematic minimum system circuit and LCD

Figure 5 displays the signal conditioning circuit using LM324 IC with 4 op-amps. Out of the four op-amps only three are used.

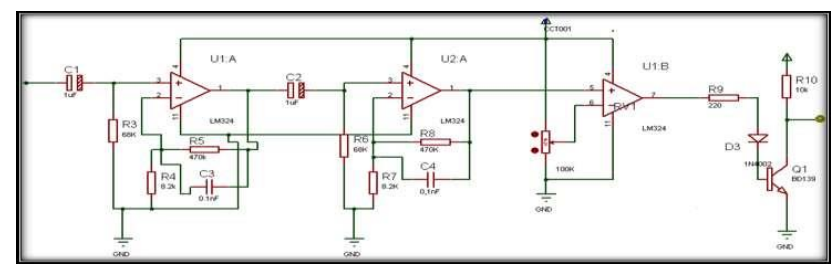

Fig. 5. Signal conditioning circuit

A stable mono circuit functions as a trigger and generates output from a signal conditioning circuit as shown in Figure 6.

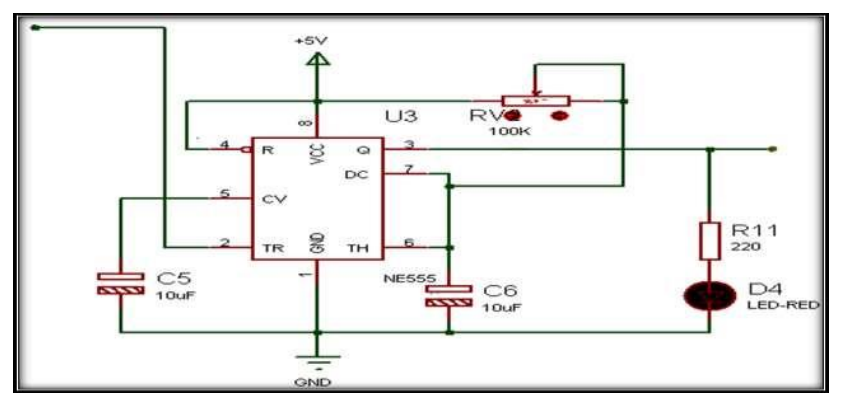

Fig. 6. Monostable circuit

After designing hardware and software, measurements are performed by comparing the average value of the division of the amount of data taken or measured by the number of data retrieval and the number of measurements.

\section{RESULT AND DISCUSSIONS}

The performance of the proposed device in the measurement of BPM and body temperature is satisfactory. Figure 7 shows pulse oximeter and thermometer as the comparison device.

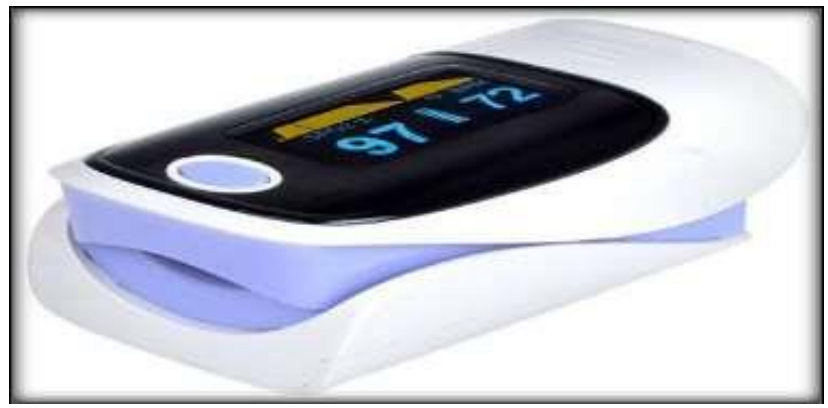

Fig. 7. Pulse oximetry

The test results carried out by calculating body temperature and heart rate to 20 people, with three different activities as it is presented in Table 1. The table shows that activity affects the number of heartbeats and body temperature.

TABLE I. DATA COLLECTION Results

\begin{tabular}{|c|l|c|c|}
\hline Name & Condition & Average HHR & Average TTEMP \\
\hline Andi & Relax & 101 & 36.28 \\
\hline & Walk & 106 & 35.18 \\
\hline & Exercises & 121 & 36.42 \\
\hline Afif & Relax & 96 & 36.88 \\
\hline & Walk & 110 & 36.22 \\
\hline & Exercises & 125 & 36.12 \\
\hline Sultan & Relax & 98.4 & 37.36 \\
\hline & Walk & 102 & 37.58 \\
\hline & Exercises & 120 & 36.96 \\
\hline
\end{tabular}

The measurements using the designed device and the pulse oximetry as the comparison device was carried out alternately in a short time lag but with the same body condition. The results showed that the smallest heart rate error was $0.17 \%$ when the measurements carried out after exercising with an average value of heart rate measurement of 120 BPM. The greatest heart rate error $1.01 \%$ was obtained at relax conditions with the average heart rate value of 80 BPM. The smallest error value in the body temperature measurement was $05 \%$, while the biggest error was during a sports condition with error value of $0.98 \%$ with an average body temperature measurement of $36.96^{\circ} \mathrm{C}$.

\section{CONCLUSIONS}

Using a photodiode sensor as the receiver and infrared LED as the transmitter for heart rate measurement is magnificent because the sensitivity of the sensor is very helpful when conducting tests and data collection. The device uses an LM35 sensor as a measurement of body temperature. The results of the measurement are displayed on the LCD. The error rate generated after measuring and calculating the lowest BPM that is $0.17 \%$ and the biggest BPM error is $1.01 \%$. While the body temperature error at least $0.05 \%$ and the biggest body temperature error is $0.98 \%$. Based on the results of measurements and testing the average heart rate error results were $0.46 \%$ and the average error temperature is 
$0.43 \%$. The test results show that the device has performed well in measuring the heart rate and body temperature with acceptable errors.

\section{REFERENCES}

[1] S. S. Mohammedsheet and M. S. Aziz, "Design and implementation of digital heart rate counter by using the 8051 microcontroller," in 2018 International Conference on Engineering Technology and their Applications (IICETA), 2018, pp. 107-111.

[2] S. Trivedi and A. N. Cheeran, "Android based health parameter monitoring," in 2017 International Conference on Intelligent Computing and Control Systems (ICICCS), 2017, pp. 1145-1149.

[3] A. Valipour and R. Abbasi-Kesbi, "A heartbeat and respiration rate sensor based on phonocardiogram for healthcare applications," in 2017 Iranian Conference on Electrical Engineering (ICEE), 2017, pp. $45-48$.

[4] A. Lichtman, R. Uzsak, M. Svetlak, and P. Fuchs, "A Smart Electrocardiogram Monitoring System on Android," in 2018 New Trends in Signal Processing (NTSP), 2018, pp. 1-5.

[5] R. Patil, P. Bais, K. Baviskar, S. Shevate, and M. Kalyani, "An Android Application for Driver Assistance and Event Alert System Using Ultrasonic Sensor and Heart Rate Sensor," in 2018 Fourth International Conference on Computing Communication Control and Automation (ICCUBEA), 2018, pp. 1-4.

[6] M. A. Al-Shaher and N. J. Al-Khafaji, "E-healthcare system to monitor vital signs," in 2017 9th International Conference on Electronics, Computers and Artificial Intelligence (ECAI), 2017, vol. 2017-Janua, pp. 1-5.

[7] P. Wasnik and A. Jeyakumar, "Monitoring stress level parameters of frequent computer users," in 2016 International Conference on Communication and Signal Processing (ICCSP), 2016, pp. 17531757.

[8] K. Aziz, S. Tarapiah, S. H. Ismail, and S. Atalla, "Smart real-time healthcare monitoring and tracking system using GSM/GPS technologies," in 2016 3rd MEC International Conference on Big Data and Smart City (ICBDSC), 2016, pp. 1-7.

[9] K. A. D. Y. L. Kuruppuachchi, M. D. R. Perera, and R. G. N. Meegama, "Wireless sensor node for simultaneous monitoring of health parameters," in 2015 Fifteenth International Conference on Advances in ICT for Emerging Regions (ICTer), 2015, pp. 259-264.

[10] S. A. Kokalki, A. R. Mali, P. A. Mundada, and R. H. Sontakke, "Smart health band using IoT," in 2017 IEEE International Conference on Power, Control, Signals and Instrumentation Engineering (ICPCSI), 2017, pp. 1683-1687.

[11] V. K. M. Anand, P. S. B. Nisar, G. D. Naresh, R. S. Nagendra, and S. Mithun, "An improved performance of home E-health portable monitoring system," in 2017 2nd IEEE International Conference on Recent Trends in Electronics, Information \& Communication Technology (RTEICT), 2017, pp. 2222-2226.

[12] A. S. Mahmood, E. Jafer, S. Hussain, and X. Fernando, "Wireless body area network development for remote patient health observing," in 2017 IEEE Canada International Humanitarian Technology Conference (IHTC), 2017, pp. 26-31.

[13] S. Sudha, D. Indumathy, A. Lavanya, M. Nishanthi, D. M. Sheeba, and V. Anand, "Patient monitoring in the hospital management using $\mathrm{Li}-\mathrm{Fi}$," in 2016 IEEE Technological Innovations in ICT for Agriculture and Rural Development (TIAR), 2016, no. Tiar, pp. 9396.

[14] N. Asmidar, N. Binti, M. Fudzi, and N. Binti, "Development of infant incubator for clinic in the rural area of Malaysia," in 2016 IEEE EMBS Conference on Biomedical Engineering and Sciences (IECBES), 2016, pp. 331-334.
[15] Gobhinath S., Aparna V, and Azhagunacchiya R, "An automatic driver drowsiness alert system by using GSM," in 2017 11th International Conference on Intelligent Systems and Control (ISCO), 2017, pp. 125-128.

[16] S. S. Thomas, A. Saraswat, A. Shashwat, and V. Bharti, "Sensing heart beat and body temperature digitally using Arduino," in 2016 International Conference on Signal Processing, Communication, Power and Embedded System (SCOPES), 2016, pp. 1721-1724.

[17] J. Priyadharshini, "Development of embedded web server for health care system using E-card," in 2017 International Conference on Algorithms, Methodology, Models and Applications in Emerging Technologies (ICAMMAET), 5093, vol. 2017-Janua, pp. 1-5.

[18] A. Deepa and P. N. Kumar, "Patient health monitoring based on ZigBee module," in 2013 International Conference on Optical Imaging Sensor and Security (ICOSS), 2013, pp. 1-4.

[19] M. Beigl, H.-W. Gellersen, and A. Schmidt, "Mediacups: experience with design and use of computer-augmented everyday artefacts," Comput. Networks, vol. 35, no. 4, pp. 401-409, Mar. 2001.

[20] P. Lee, C. Bollensdorff, T. A. Quinn, J. P. Wuskell, L. M. Loew, and P. Kohl, "Single-sensor system for spatially resolved, continuous, and multiparametric optical mapping of cardiac tissue," Hear. Rhythm, vol. 8, no. 9, pp. 1482-1491, Sep. 2011.

[21] A. Hosainpour, M. H. Komarizade, A. Mahmoudi, and M. G. Shayesteh, "High speed detection of potato and clod using an acoustic based intelligent system," Expert Syst. Appl., vol. 38, no. 10, pp. 12101-12106, Sep. 2011.

[22] A. Kaklauskas et al., "Web-based Biometric Computer Mouse Advisory System to Analyze a User's Emotions and Work Productivity," Eng. Appl. Artif. Intell., vol. 24, no. 6, pp. 928-945, Sep. 2011.

[23] C. R. Kube and E. Bonabeau, "Cooperative transport by ants and robots,” Rob. Auton. Syst., vol. 30, no. 1-2, pp. 85-101, Jan. 2000.

[24] S. Hong, H. Kwon, S. H. Choi, and K. S. Park, "Intelligent system for drowsiness recognition based on ear canal electroencephalography with photoplethysmography and electrocardiography," Inf. Sci. (Ny)., vol. 453, pp. 302-322, 2018.

[25] H. Mansor, S. S. Meskam, N. S. Zamery, N. Q. A. M. Rusli, and R. Akmeliawati, "Portable heart rate measurement for remote health monitoring system," in 2015 10th Asian Control Conference (ASCC), 2015, no. June 2013, pp. 1-5.

[26] S. Abraham and X. Li, "A Cost-effective Wireless Sensor Network System for Indoor Air Quality Monitoring Applications," Procedia Comput. Sci., vol. 34, pp. 165-171, 2014.

[27] M. S. Ali and M. H. Bhuyan, "Design and Implementation of a LowCost Blood Pressure Measuring Device," in 2018 10th International Conference on Electrical and Computer Engineering (ICECE), 2018, pp. 309-312.

[28] A. H. T. E. De Silva, W. H. P. Sampath, N. H. L. Sameera, Y. W. R. Amarasinghe, and A. Mitani, "Development of a novel telecare system, integrated with plantar pressure measurement system," Informatics Med. Unlocked, vol. 12, no. July, pp. 98-105, 2018.

[29] S. Krishnamurthy and S. Gayathri, "Prevention of poaching of tigers using wireless sensor network," in 2017 IEEE International Conference on Antenna Innovations \& Modern Technologies for Ground, Aircraft and Satellite Applications (iAIM), 5094, pp. 1-7.

[30] L. Priya, R. Hariprasad, and R. Raghul, "Real time monitoring of vital signs using wireless technique," in 2014 International Conference on Green Computing Communication and Electrical Engineering (ICGCCEE), 2014, pp. 1-7. 